\title{
The test-retest reliability of free associations following continued associations'
}

\author{
S. JOYCE BROTSKY ${ }^{2}$, SAN FERNANDO VALLEY STATE COLLEGE \\ MARIGOLD L. LINTON, SAN DIEGO STATE COLLEGE
}

Continued associations were given by 45 Ss to 68 words. Four weeks later, $S$ s were instructed to give a single response to each of the stimulus words. Sixty-one percent of the Retest words given by Ss occurred in the Test hierarchy, 35\% in the first position. Dominance of the primary (DP), as determined from norms (Brotsky \& Linton, 1967b), was highly correlated with the number of Retest responses found in the Test hierarchy ( $r=.76)$; while frequency in the language (LF) and number of different responses ( $D R$ ) found in the norms were negatively related to the number of identical Test-Retest responses. (IAs). When LF and DR were used as multiple predictors of the occurrence of a Retest response within S's Test hierarchy, $R_{1.23}=.81$.

In an earlier investigation (Brotsky \& Linton, 1967a), 146 Ss gave free associations to 158 stimulus words on two occasions separated by 10 weeks. The probability of responding with an identical associate (IA) after 10 weeks was .32. The positive correlation between dominance of the primary (DP) and number of LAs, and the negative correlation between Thorndike-Lorge language frequency (LF) and LAs, led to the conclusion that a high degree of reliability can be predicted for words with low LF and high DP.

The present study attempted to further explore the Test-Retest rellability (TRR) of the word association test. On the assumption that momentary oscillation may determine which of several competing responses is emitted when $S$ is instructed to give only one verbal associate, the present study required that $S$ generate a hierarchy of responses to a set of stimulus words using a modification of the procedures for continued word association developed by Noble (1952) and extended by Andreas (1966). Four weeks later Swas given a Retest. It was predicted that a large proportion of S's Retest responses would be traceable to his Test hierarchy, with the largest proportion of IAs occurring early in the Test hierarchy. It was further predicted that IA would be positively correlated with DP and negatively correlated with LF and the number of different responses (DRs) given by a normative group. Method

The Ss were 45 undergraduates between the ages of 17 and 28. All Ss had been born in continental United States and had learned English as their first language. The Ss participated as part of a course requirement at San Fernando Valley State College. The data were taken from three small intact classes during class time.

The 68 stimulus words, originally chosen from the Connecticut Free Associational Norms (Bousfield, Cohen, Whitmarsh, \& Kincaid, 1961), had been used by the authors in an earlier study (Brotsky \& Linton, 1967a). The Test booklet consisted of 68 pages. Down the left side of each page, a single word was repeated 25 times, with each repetition followed by a line on which $\mathrm{S}$ was instructed to write a one-word response. The pages were individually randomized for each $S$. The Retest booklet consisted of three pages, on which were dittoed the 68 different words, each followed by a line. All Ss responded to the words of the Retest in the same serial order.

The general instructions for the Test were taken from Noble's (1952) report. The Ss were instructed to say the stimulus word to themselves before writing each response. After $45 \mathrm{sec}, \mathrm{E}$ said the word "Turn" in a firm voice. All Ss complied with the instructions. No practice page was used. Following each 15-20 pages $E$ said "Penclls down," and Ss were instructed to rest. After $10 \mathrm{sec} E$ said "Turn," and Ss resumed the task.

The Retest was conducted four weeks later. Standard free association instructions were used (Russell \& Jenkins, 1954). The $E$ wrote the time on the blackboard at 1 min intervals, and Ss were instructed to write the time of completion at the bottom of their booklets. Results and Discussion

As part of an earlier study, a set of norms had been developed on the basis of the responses of $146 \mathrm{Ss}$ to 158 words (Brotsky \& Linton, 1967b). Both DP and the number of DRs given to each of the stimulus words were derived from these norms. To determine the number of IAs and their position in S's Test hierarchy, Retest responses were coded as $0,1,2,3,4$, etc. A designation of 0 was used when the Retest response did not occur in S's Test hierarchy, while 1, 2, 3, etc indicated that the Retest word was the first, second, third, etc. word in S's Test hierarchy. For the purpose of scoring, a response that was plural in form was considered identical to the singular. To avoid arbitrary decisions in scoring, other variations or misspellings were considered separate entries.

The number of responses made by the $45 \mathrm{Ss}$ to the 68 stimulus words ranged from 294 for MOCK to 488 for TENNIS, with a $M=387$, a median $=384.5$, and an $\mathrm{SD}=37.97$. The total number of responses given by any $\mathrm{S}$ to the stimulus words ranged from 268 to 894 with a $M=585$, a median $=610$, and an $\mathrm{SD}=148.84$. Of the Retest words given by the Ss, $61 \%$ occurred at some point in their Test hierarchy: $35 \%$ of the Retest words occurred in the first position in the Testhierarchy, $10 \%$ occurred in the second position, $4 \%$ in the third position, $4 \%$ in the fourth position, $2 \%$ in the fifth position, $2 \%$ in the 
sixth position, $1 \%$ in the seventh position, $1 \%$ in the eighth position, and regularly decreasing fractions of $1 \%$ in positions 9-13. No IA occurred beyond the 14 th position in the hierarchy.

When the probability of giving an IA in both the first position of the Test hierarchy and on the Retest on the continued association task after four weeks (.35) was compared with the probability of giving the same word on the Test and Retest (.32) found in an earlier free association study (Brotsky \& Linton, 1967a), the difference was not statistically reliable $(F=3.22, \mathrm{df}=1 / 189$, p> .05). Thus, about $1 / 3$ of the first associates given on a continued association Test were given on a Retest. Although an additional $1 / 3$ of the Retest responses were found in the continued association hierarchies produced by $S s$ in $45 \mathrm{sec}$, over $1 / 3$ of the Retest responses were not accounted for. Inspection of the data suggested that it was unlikely that any substantial proportion of the Retest words would have been found in hierarchies produced by the more typical (Noble, 1952; Andreas, 1966) $1 \mathrm{~min}$ association period.

A product moment correlation was computed between the DP for each of the 68 words as determined from the norms and the number of IAs in the first position of the Test hierarchy, and yielded $r=.81(d f=66, p<.01)$. The correlation between DP and number of IAs in any position in the Test hierarchy was $r=.76$ (df $=66, p<.01$ ).

As was found to be the case in an earlier study (Brotsky \& Linton, 1967a), those Ss who gave many primary (P) responses as determined from the norms tended to show a higher degree of TRR than Ss who gave fewer $P$ responses. The correlation across Ss between number of $P$ responses on the Retest and the number of IAs in the first position of the Testhierarchy was $r=.53$ ( $d f=43, p<.01$ ); the correlation between number of $P$ responses on the Retest and number of IAs in any position in the Test hierarchy was $r=.57(d f=43, p<.01)$.

The correlation between the number of DRs given to the 68 words by the normative group and the number of IAs in the first position of the Test hierarchy $(r=-.72$, $\mathrm{df}=66, \mathrm{p}<.01$ ) was strongly negative, as was the correlation between DR and the number of IAs which appeared in any position in the Test hierarchy $(r=-.79, \mathrm{df}=66, \mathrm{p}$ $<.01$ ). A negative correlation was also found between number of DRs and the number of words in the continued association hlerarchy (TH) elicited from the $45 \mathrm{Ss}$ to each of the 68 words on the Test $(r=-.41, \mathrm{df}=66, p<.01)$.
Although it might be predicted that IAs would be more likely to occur in the Retest for those words which elicited large THs in the continued association Test, the relationship between the number of IAs in any position of the hierarchy and TH was modest though statistically reliable $(r=.28, d f=66, p<.05)$.

Correlations were computed between LF and DP ( $r$ $=-.28$, df $=66, p<.05) ; \mathrm{LF}$ and number of LAs in the first position of the Test hierarchy $(r=-.35$, df $=66, p<.01)$; LF and the number of IAs that occurred in any position in the Test hierarchy $(r=-.48, d f=66, p<.01)$; and $L F$ and DR ( $r=.39, \mathrm{df}=66, p<.01)$. When $L F$ and $D R$ were used as multiple predictors of the occurrence of an IA on the Retest in the first position of the Test hierarchy, $R_{1.23}=.72$ (df $\left.=65, p<.01\right)$. When $L F$ and $D R$ were used as multiple predictors of an IA in any position of the Test hierarchy, $R_{1,23}=.81(d f=65, p<.01)$. These findings suggested that when high LF words acquire many associates whose probability of occurrence is high, response competition is likely to occur due to the many opportunities for intrusions, and low TRR would be predicted. When both LF and DR are low and DP is high, there would be little response competition, and high TRR would be predicted.

\section{References}

ANDREAS, B. G. Indicants of response strength hierarchies in continued word association. Psychon. Sci, 1966, 6, 447-448.

BOUSFIELD, W. A., COHEN, B. H., WHITMARSH, C. A., \& KINCAID, W. P. The Connecticut free associational norms. Tech. Rep. No. 35, 1961, University of Connecticut, Contract Nonr 631(00) Office of Naval Research.

BROTSKY, S. J., \& LINTON, M. L. The Test-retest reliability of free association norms. Psychon. Sci, 1967a, 8, 425-426.

BROTSKY, S. J., \& LINTON, M. L. The San Fernando Valley State College word association norms. Tech. Rep. No. 1, 1967b, San Fernando Valley State College, Research Grant 4.259.01, San Fernando Valley State College Foundation.

NOBLE, C. E. An analysis of meaning. Psychol Rev., 1952, 59, 421-430.

RUSSELL, W. A., \& JENKINS, J. J. The complete Minnesota norms for responses to 100 words from the Kent-Rosanoff Word Association Test. Tech. Rep. No. 11, 1954, University of Minnesota Contract N8 Ont 66216.

THORNDIKE, E. L., \& LORGE, I. The teachers word book of 30,000 words. New York: Columbia University Press, 1944.

Note

1. This research was supported in part by a Research Grant to the first author from the San Fernando Valley State College Foundation and by a Faculty Research Award to the second author from the San Diego State College Foundation.

2. Now Post-doctoral Fellow; Department of Social Relations, Harvard University, Cambridge, Massachusetts. 